\title{
A Conceptual Framework of a Streamlined Extended Technology Acceptance Model for Mobile Application Adoption
}

\author{
John Dah \\ Faculty of Information Management, Universiti Teknologi MARA (UiTM), \\ 40150 Shah Alam, Selangor, Malaysia \\ E-mail: Barrybarryjohnjohn@gmail.com, yatihussin@uitm.edu.my \\ Norhayati Hussin (Corresponding author) \\ Faculty of Information Management, Universiti Teknologi MARA (UiTM), \\ 40150 Shah Alam, Selangor, Malaysia \\ E-mail: yatihussin@uitm.edu.my
}

Received: March 11, 2021 Accepted: April 20, $2021 \quad$ Published: May 15, 2021

doi:10.5296/ijssr.v9i2.18649 URL: https://doi.org/10.5296/ijssr.v9i2.18649

\begin{abstract}
Information systems have enjoyed their fair share of success over the years. Various technology adoption theories and models have been used to understand the factors that cause users to harmonize with new technology. Although the technology acceptance model is the most widely used of all technology adoption theories and also gives room for the addition of an external variable, many experts believe that a rudimentary construct should govern its core variables in the field with which it is applied. This believes system birthed the TAM 2 model, which came with an external variable to the extant TAM model. One of the firm beliefs upheld by the TAM model is that "perceived ease of use" fuels users' intention to accept and adopt new IS systems or otherwise. The TAM 2 or Extended TAM model is driven by the notion that a unique and influential construct in the context of the technology or the object being assessed would improve the result's accuracy. Therefore, the purpose of this study is to introduce mobile skillfulness as an influential construct that regulates the perception of ease and usefulness in the technology acceptance model for the assessment of mobile-related technologies. This study aims to develop an extended model from the extant TAM model that
\end{abstract}




\section{Macrothink}

International Journal of Social Science Research

ISSN $2327-5510$ 2021, Vol. 9, No. 2

befits the acceptance assessments of mobile-related technologies such as applications and mobile games. The method used in this article is a literature survey to explore and understand the technology acceptance model (TAM), which would match mobile-related technology. The comprehensive conceptual model has been constructed in this article.

Keywords: information management, mobile application, technology acceptance model, technology adoption, user acceptance 


\section{Introduction}

A like-trait amongst information system and information technology professionals is to understand how systems and infrastructures work and understand the factors and behaviours that psychologically nudge users to come to accept and adopt an IT/IS system (Clark, Drake, Kapp, \& Wong, 1985). Moreover, information also relies on the users' information behaviour in the organization (Hussin \& Jamaludin, 2018). Diverse theories and models have arisen to explain the acceptance of new technology among users (Rondan-Cataluña, Arenas-Gaitán, \& Ramírez-Correa, 2015). Some of these theories include; the Theory of Reasoned Action (TRA), the Model of Personal Computer Utilization (MPCU), Motivational Model (MM), Unified Theory of Acceptance and Use of Technology (UTAUT), Theory of Planned Behaviour (TPB), and the renowned Technology Acceptance Model (TAM). Of all these technology adoption theories and models, the technology acceptance model developed by Davies (1989) stands as the most widely used framework for measuring the acceptance and adoption of information systems or at least new technologies. The TAM model thrives on the strength of two proven constructs, perceived usefulness and perceived ease of use. Perceived usefulness speaks of how using a system will improve job performance, and perceived ease of use refers to the degree to which a user believes that using a particular system would be free of effort (Jahangir \& Begum, 2008). These two constructs knit to influence the intentions of a user to use any new technology or system. Since information systems assume diverse classes in terms of functionality and interactions (Hasan Al-Mamary, Shamsuddin, \& Aziati, 2014), researchers have over the years, modified the TAM model to include newer constructs that would suit the class of the system being assessed (Emad, El-Bakry, \& Asem, 2016). This alteration gave rise to the TAM 2 model or the extended TAM model. The extended TAM model introduces an external variable that influences the initial root constructs, perceived usefulness, and perceived ease of use (Holden \& Karsh, 2010). The Extended TAM in itself does not define what the external variable is or what it should be, nor does it instantiate it as a constant construct in the model (Hong \& Yu, 2018). This pliability makes the Extended TAM model fit for every category of information system and enable researchers to insert a construct that would befit the context of the system being assessed (Sharifeh, 2017). This pattern of thinking makes a suggestion through this instance, a study that seeks the test the acceptability of new computer software using the TAM 2 model should use a simple construct such as "computer skillfulness" or "computer self-efficacy" as an external variable in the context of computer usage that will influence the entirety of the framework. In that similitude, the approach entails that a study that seeks to test mobile apps' acceptability should use "mobile skillfulness" or "mobile self-efficacy" as an external variable in mobile users' domain to influence the entire model. This proposition's motivation is that their skillfulness or self-efficacy mostly influences users' perception of ease and usefulness in operating a system, device, or any IS/IT system (Fauzi et al., 2017). Prior experience with an IS/IT system can be beneficial in determining the acceptability of the system among users since perceived ease of use and perceived usefulness are two pillars that buttress the intention of a user to adopt a system. 


\section{Literature Review}

Technology surge is rapidly changing and also become the foremost concern (Saodi et al., 2018). One example of a technology surge is the mobile application. Mobile applications have been here for a while, and statistics predict that they are here to stay. Many mobile apps stem from a bigger trunk of computer software or webpages optimized to function efficiently on mobile devices and other mobile-compatible platforms and interfaces. However, these mobile applications thrive on their harmony with which they receive from users and potential users (Malik, Suresh, \& Sharma, 2017). Apps that may seem valuable and nearly impossible to ignore are being shunned due to their unfriendliness towards users. This leads to the grill of "what compels users to accept and adopt an app or a system." The TAM as a technology adoption model has helped answer this question. Various studies have used the TAM model and the extended TAM models to understand how users come to accept a new technology (Chen, Rong, Ma, Qu, \& Xiong, 2017).

Fishbein and Ajzen's Theory of Reasoned Action (TRA) and Davis' renowned Technology Acceptance Model (TAM) provide academic contexts for measuring beliefs to predict users' future behaviours towards new technology. The TRA birthed the TAM framework, which became specific for modelling user acceptance of information systems. TAM suggests that two particular beliefs, perceived usefulness and perceived ease of use, are of central relevance for predicting computer user acceptance behaviours (Hubona \& Kennick, 1996). Davis's first technology acceptance model consisted of the fundamental variables that are perceived ease of use and perceived usefulness. This model was used in a study by (Diop, Zhao, \& Duy, 2019) in contrast with other modified TAM models. The second TAM theory, known as the TAM 2, incorporates the subjective norm, voluntariness, and image. These are three interrelated social forms. These forms help to measure if an individual will adopt or reject a new system. The three interrelated forms posed an influence on perceived usefulness and were moderated by voluntariness and experience. Again, Venkatesh and Davis (2000) indicated that the cognitive determinants of perceived usefulness in TAM 2 could be described as perceived ease of use, output, output quality, and job relevance. The latest technology acceptance model is the TAM 3 developed by Venkatesh and Bala (2008). The TAM 3 incorporate the initial constructs found In TAM 2 while externalizing five additional variables to influence the model. The newly introduced variables consisted of; computer-self efficacy, perception of external control, computer anxiety, computer playfulness, perceived enjoyment and perceived objectivity. Experience as a construct moderated the newly added external constructs except for computer-self efficacy.

\subsection{The Future Path and Present-Day Stand of the Technology Acceptance Model}

The first technology acceptance model (TAM) is the least complex in terms of hypotheses and variables. In the later future, adding more constructs to the TAM model to birth the TAM 2 and TAM 3 served to improve the accuracy and reliability of the model in providing precise results. The addition seemed to create some complexities that may discourage researchers from adopting the TAM 3 (Ajibade, 2018). One of the argument and criticism of the TAM 3 is that the model could satisfactorily explain individual behaviour, which is excellent. Still, 
due to its vast and precise external variables, criticism arose that the model itself is not robust enough to explain users' behaviour about buying, rejecting or accepting to use certain technologies (Hai, Hasnain, \& Kazmi, 2015). This further suggests that many external variables may not necessarily translate to accurate results in measuring certain technologies. A study that measured why individuals opt-in for technology entertainment such as video games perceived usefulness as a core construct failed to impact users' intentions. The study explained that users who indulge in technology entertainment do so to kill time (Hsu \& $\mathrm{Lu}$, 2003). Among other reasons, the TAM has thrived in technology adoption theories due to its simplicity in comprehension and application (King \& He, 2006). Therefore, the addition of more constructs could be a positive step towards the flawlessness of results, but it would create complexities that would cause researchers to shy away from the model (Fatimah \& Rahman, 2019). This is because the average researcher would opt to use a less complicated framework that would provide a good result than go for a complex model that would require effort to produce accurate results, seeing that the differences in outcomes might be minimal and insignificant (Sia \& Ming, 2010). As some studies report, in the context of organizational IS implementation, some of the TAM's external variables, such as subjective norm, failed to influence perceived usefulness or perceived ease of use. This phenomenon was explained by Ajibade (2018) to be that employees who adopt and use IS system for work-related purposes do so compelled by their job demands and not necessarily by choice or sheared will. Thus, the users' perception of the system's ease or usefulness is not affected by the external variables.

\subsection{Meticulousness for Accuracy or Simplicity for Adoption? The Symmetry of the TAM Model}

One of the firm beliefs upheld by the TAM model is that "perceived ease of use" fuels users' intention to accept and adopt new IS systems or otherwise. However, the TAM 3 model is hypocritical towards this thinking pattern and contradicts the ideology as the numerous external variables added on the TAM 3 create more perception of difficulty than ease (Iqbal, Naeem Khan, \& Riaz Malik, 2017). Although it can be argued that those external variables may improve the accuracy of results in a survey, it still renders the model exhaustive and rigorous (Al-Gahtani, 2016). Thus, a balance must be struck between its meticulousness and ease in adoption if, at all, the TAM model wishes to retain its spot as the most widely used model of technology adoption theories. This balancing is required to ensure that the model does not compromise ease of usage over thoroughness or vice versa. The model still retains its simplicity and is a relatively reliable framework for assessing IS systems' adoption and acceptance. Wherefore, this study postulates the concept of a uni-external variable that can averagely surrogate all other external variables to simplify the TAM 3 model.

\subsection{Mobile Skillfulness; An Archetype of the External Construct for Mobile-Related Technologies}

The need for a lucid external variable has been established to be eminent, or at least if the TAM model is expected to thrive in coming dispensations. The external construct is likely to be of a primitive nature because it encapsulates the fundamental behaviours or skill of 
average users in the context of the technology or the IS system being assessed (Sharifeh, 2017). Therefore, mobile-related systems such as mobile applications and games, experiences, and mastery in operating mobile phones would serve as the basis for an assessment; this can be termed "Mobile skillfulness" (Lu \& Yu - Jen Su, 2009). Implementing mobile skillfulness as an external variable for assessing mobile-related technologies has two significant things to the model: (a) eliminates the numerous external variables that make the model appear complicated, (b) condenses the external multi-constructs into a single variable that simplifies the model. This unification of the external constructs can be applied to mobile technologies alone, and other IS system context. For instance, in assessing the adoption of computer software, "computer skillfulness" or "computer self-efficacy" can be used as an external construct that encapsulates and proxy's all the other precise variables. By doing this, the constructs are condensed. The model is simplified, and the propensity for adoption and application rises. It is because the perception of ease has been heightened through a less complex model.

\section{Research Methodology}

The literature survey has been used to explore and discover the previous studies related to the technology acceptance model (TAM) used by various areas. A literature survey is documentation of a comprehensive review of the published and unpublished work from secondary sources about the broad problem areas (Ozmen, 2016). The published and unpublished data has been used to dig out the study's core root related to the technology acceptance model and variables used in this model by previous scholars. Published and unpublished data has been taken from secondary data sources. Secondary data sources consist of e-government publications, websites, books, journal articles, internal records (Ajayi, 2017). According to Valcheva (2021), secondary data represent the data or information collected for another purpose and relevant to the current research needs. In this paper, the author has assessed the various journal articles to determine and identify the variable frequently used for the technology acceptance model to construct the comprehensive model for evaluating people's acceptance of mobile-related technology. The author maintained two main variables, which are "perceived usefulness" and "perceived ease of use" when constructing this model. The opinion of Davis (1989, p. 320), who the creator of the technology acceptance model, has been used, and he stated the two important variables "Perceived Usefulness" and "Perceived Ease of Use" will influence the perception in determining the adoption of technology while suggesting user intention to develop new skills in constructing the model towards adoption of technology. These variables undoubtedly significantly influence mobile-related technology adoption and contribute and expand towards the body of knowledge within this area of study.

\section{Findings and Recommendations}

This study's theoretical framework stands upon several different theories, frameworks, and models used in time past. The chiefest of them all is the technology acceptance model (TAM). The ideology here is that, of all the external variables found on the TAM 3 model, a uni-variable would be created to encapsulate and condense them into a single rudimentary 


\section{Ml Macrothink}

external variable. A method is required to consolidate these variables into a single variable that at least represents each of the condensed variables, of which this study uses the "average" or "mean" method found in statistics and mathematics (García Cruz \& Garret, 2008). The idea of the "mean" works to find a central tendency or a relative midpoint-value representing the entire data found in a data set. The mean stands as the central value representation of the whole data set with which individuals can use to understand the central tendency of a data set intuitively. It is calculated by summing the total value and dividing it by the data set's unit number. In that similitude, although the mean of the external variables of the TAM 3 cannot be quantitatively calculated using the "mean principle," this study is qualitative looks at each of the external variables. It sums them up into a broader rudimentary variable (such as a latent variable) that can vaguely represent all the condensed constructs. Since the information system being assessed could vary based on different parameters and usage, the rudimentary variable would differ contextually. Therefore, the conceptual model for mobile related-technologies is proposed in Figure1.

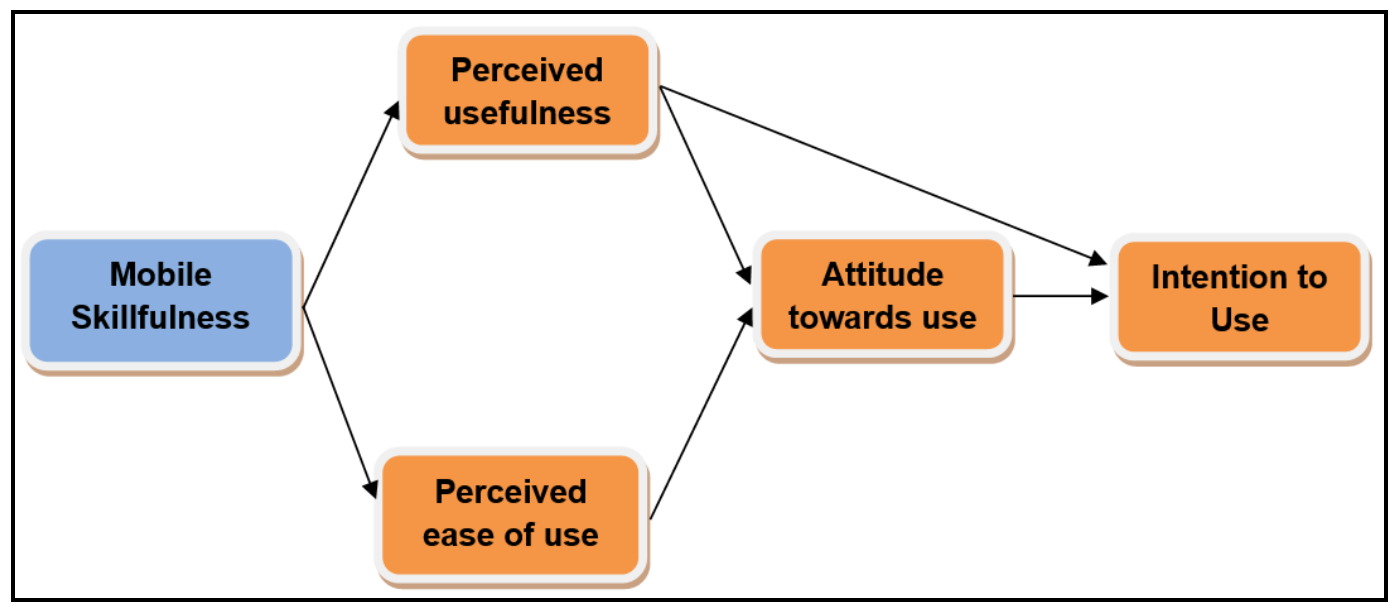

Figure 1. A conceptual framework for assessing mobile-related technology

\section{Conclusion}

The variable "Mobile skillfulness" that substituted the external variables on the TAM 3 framework is a derivative of an enormous construct that covers all the other precise variables. The purpose of this consolidation is to simplify the TAM model while still retaining its comprehensibility. The external construct may vary depending on the system being assessed. Thus, the external variable must be developed contextually to suit the systems' assessment. As in the context of mobile technologies, "mobile skillfulness" covers all the external variables as the conceptual model proposed.

\section{Acknowledgement}

This paper is funded by the Fundamental Research Grant Scheme (FRGS), Ministry of Higher Education Malaysia. Reference Number: 600-IRMI/FRGS 5/3 (324/2019). 


\section{References}

Ajayi, O. V. (2017). Distinguish between primary sources of data and secondary sources of data. Retrieved March, 2021, from https://www.researchgate.net/publication/320010397_Primary_Sources_of_Data_and_Secon dary_Sources_of_Data

Ajibade, P. (2018). Technology Acceptance Model Limitations and Criticisms: Exploring the Practical Applications and Use in Technology-related Studies, Mixed-method, and Qualitative Researches. Retrieved from http://digitalcommons.unl.edu/libphilprac/1941

Al-Gahtani, S. S. (2016). Empirical investigation of e-learning acceptance and assimilation: A structural equation model. Applied Computing and Informatics, 12(1), 27-50. https://doi.org/10.1016/j.aci.2014.09.001

Chen, H., Rong, W., Ma, X., Qu, Y., \& Xiong, Z. (2017). An Extended Technology Acceptance Model for Mobile Social Gaming Service Popularity Analysis. Mobile Information Systems, 2017. https://doi.org/10.1155/2017/3906953

Clark, F., Drake, P., Kapp, M., \& Wong, P. (1985). User Acceptance of Information Technology Through Prototyping (August, pp. 703-708).

Diop, E. B., Zhao, S., \& Duy, T. V. (2019). An extension of the technology acceptance model for understanding travelers' adoption of variable message signs. PLOS ONE, 14(4), e0216007. https://doi.org/10.1371/journal.pone.0216007

Emad, H., El-Bakry, H. M., \& Asem, A. (2016). A Modified Technology Acceptance Model for Health Informatics A Modified Technology Acceptance Model for Health Informatics. International Journal of Artifical Intelligence and Mechatronics, 4(4), 153-161.

Fatimah, S., \& Rahman, A. (2019). A Technology Acceptance Model (TAM): Malaysian ESL Lecturers' Attitude in Adapting Flipped Learning (Technology Acceptance Model (TAM): Sikap Pensyarah ESL di Malaysia dalam Penyesuaian Pembelajaran Flipped). Jurnal Pendidikan Malaysia, 44(01SI). https://doi.org/10.17576/JPEN-2019-44.01SI-04

Fauzi, A., Ayub, M., Zaini, S. H., Luan, W. S., Marzuki, W., \& Jaafar, W. (2017). The Influence of Mobile Self-efficacy, Personal Innovativeness and Readiness towards Students' Attitudes towards the use of Mobile Apps in Learning and Teaching. International Journal of Academic Research in Business and Social Sciences, 7, 364. https://doi.org/10.6007/IJARBSS/v7-i14/3673

García Cruz, J. A., \& Garret, A. J. (2008). Understanding the Arithmetic Mean: A Study with Secondary and University Students. Research in Mathematical Education, 12(1), 49-66.

Hai, L. C., Hasnain, S., \& Kazmi, A. (2015). Dynamic Support of Government in Online Shopping. Asian Social Science, 11(22), 1. https://doi.org/10.5539/ass.v11n22p1

Hasan Al-Mamary, Y., Shamsuddin, A., \& Aziati, N. (2014). The Role of Different Types of Information Systems in Business Organizations: A Review by Yaser Hasan Al-Mamary, Alina 
Shamsuddin, A.H. Nor Aziati. International Journal of Research, 1(7), 333-339. https://doi.org/10.26524/jms.2014.16

Holden, R. J., \& Karsh, B. T. (2010, February). The Technology Acceptance Model: Its past and its future in health care. Journal of Biomedical Informatics, 43(1), 159-172. https://doi.org/10.1016/j.jbi.2009.07.002

Hong, S. H., \& Yu, J. H. (2018). Identification of external variables for the Technology Acceptance Model (TAM) in the assessment of BIM application for mobile devices. Conf. Ser.: Mater. Sci. Eng., 401, 012027. https://doi.org/10.1088/1757-899X/401/1/012027

Hsu, C.-L., \& Lu, H.-P. (2003). Why do people play on-line games? An extended TAM with social influences and flow experience. Information \& Management, 41(7), 853-868. https://doi.org/10.1016/j.im.2003.08.014

Hussin, N., \& Jamaludin, A. (2018). Information Behavior of Managers (IBM) and Strategic Information Use (SIU) in Malaysian Industries. International Journal of Engineering \& Technology, 7(3), 249-252. https://doi.org/10.14419/ijet.v7i3.7.16362

Iqbal, S., Naeem Khan, M., \& Riaz Malik, I. (2017). Mobile Phone Usage and Students' Perception towards M-Learning: A Case of Undergraduate Students in Pakistan (Vol. 32). Retrieved from https://files.eric.ed.gov/fulltext/EJ1154625.pdf

Jahangir, N., \& Begum, N. (2008). The role of perceived usefulness, perceived ease of use, security and privacy, and customer attitude to engender customer adaptation in the context of electronic banking. African Journal of Business Management, 2(1), 32-40. Retrieved from http://www.academicjournals.org/AJBM

King, W. R., \& He, J. (2006). A meta-analysis of the technology acceptance model. Information \& Management, 73(6), 740-755. https://doi.org/10.1016/j.im.2006.05.003

Lu, H., \& Yu - Jen Su, P. (2009). Factors affecting purchase intention on mobile shopping web sites. Internet Research, 19(4), 442-458. https://doi.org/10.1108/10662240910981399

Malik, A., Suresh, S., \& Sharma, S. (2017). Factors influencing consumers' attitude towards adoption and continuous use of mobile applications: A conceptual model. In Procedia Computer Science (Vol. 122, pp. 106-113). Elsevier B.V. https://doi.org/10.1016/j.procs.2017.11.348

Ozmen, S. (2016). Seminar in Thesis. Retrieved March 2021, from https://slideplayer.com/slide/7230872/

Rondan-Cataluña, F. J., Arenas-Gaitán, J., \& Ramírez-Correa, P. E. (2015). A comparison of the different versions of popular technology acceptance models a non-linear perspective. Kybernetes, 44(5), 788-805. https://doi.org/10.1108/K-09-2014-0184

Saodi, N. F. M., Idris, M. S. I., Saharuddin, N. A., Farik, S., Yatin, M., Hussin, N., \& Ab Rahman, A. (2018). The Emerging Roles of Information Management in Government Agencies. International Journal of Engineering \& Technology, 7(3), 245-248. 


\section{Macrothink \\ International Journal of Social Science Research \\ ISSN 2327-5510 2021, Vol. 9, No. 2}

https://doi.org/10.14419/ijet.v7i3.7.16361

Sharifeh, S. (2017). Developing Technology Acceptance Models for Decision Making in Urban Management. MOJ Civil Engineering, 2(6). https://doi.org/10.15406/mojce.2017.02.00050

Sia, J., \& Ming, K. (2010). Institutional Factors Influencing Students' College Choice Decision in Malaysia: A Conceptual Framework. In International Journal of Business and Social Science (Vol. 1). Retrieved from www.ijbssnet.com

Valcheva, S. (2021). Secondary Data: Advantages, Disadvantages, Sources, Types. Intelspot. Retrieved March 2021, from http://www.intellspot.com/secondary-data/

\section{Copyrights}

Copyright for this article is retained by the author(s), with first publication rights granted to the journal.

This is an open-access article distributed under the terms and conditions of the Creative Commons Attribution license (http://creativecommons.org/licenses/by/4.0/). 